\title{
EXPERT CONTROL SYSTEM OF SHIPPING OPERATION ON THE GABCIKOVO PROJECT
}

\author{
${ }^{1}$ Peter ŠULEK, ${ }^{2}$ Tomáš KINCZER* \\ ${ }^{1,2}$ Faculty of Civil Engineering, Slovak University of Technology in Bratislava, Slovak \\ Republic, e-mail: ${ }^{1}$ peter.sulek@stuba.sk, ${ }^{2}$ tomas.kinczer@stuba.sk
}

Received 19 December 2017; accepted 16 October 2018

\begin{abstract}
Task of shipping operations control of the Gabčíkovo Project is to synchronize several requirements. These come from versatility of GAP and must meet with the following goals. The operation of GAP must be effective (maximization of the ship locks capacity, maximization of income from electricity production in hydropower plant); reliability of operation of the ship locks must not be limited or endangered by defects on technology parts of the ship locks caused by illegal parameters of water flow in the filling and emptying system; and shipping safety must not be endangered or limited by unsuitable parameters of river way (navigable depth below minimal shipping depths in ford sections caused by flow changes on Gabčíkovo Project and ships crushing into riverbed of the Danube river).

By taking these goals into account, it is possible, in general, to define operation of Gabčíkovo Project as complex multi-criteria optimization task with many technological, water management, energetic and environmental constrains. Standard approach in solving this problem includes elaboration of optimization or simulation model of Gabčíkovo Project operation. If mathematical description of problem does not exist, 'classic' expert control system management must be applied. Based on above stated criteria, most effective approach to this problem appears to be creating software application that combines both approaches.

In this case, expert control system of shipping operation on Gabčíkovo Project will be software application to model hydraulic links and hydraulic regimes (discharges, water levels and flow velocities) based on relevant inputs on the ship locks and whole section of the Danube river, that is affected by Gabčíkovo Project operation.

The paper describes possible optimization solution for achieving above mentioned goals. Architecture of proposed expert control system is described in the paper and the focus is mainly
\end{abstract}

\footnotetext{
${ }^{*}$ Corresponding Author
} 
on analyzing suitability of heuristic optimization methods for solving above the stated optimization problems.

Keywords: Gabčíkovo project, Danube, Expert control systems, Optimization model, Heuristic optimization methods

\section{Introduction}

The Gabčíkovo Project (GAP) is a type of the multipurpose water project [1]. It provides the international shipping, flood protection, required withdraws and it uses as energy source too (see Fig. 1 and Fig. 2).

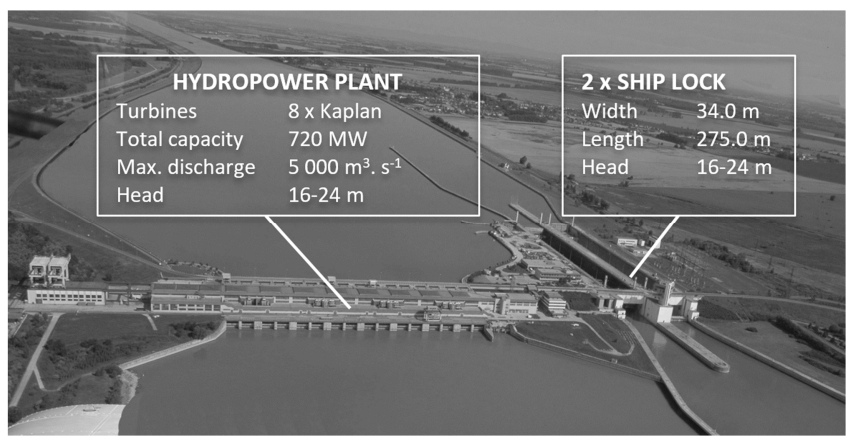

Fig. 1. The Gabčíkovo Dam

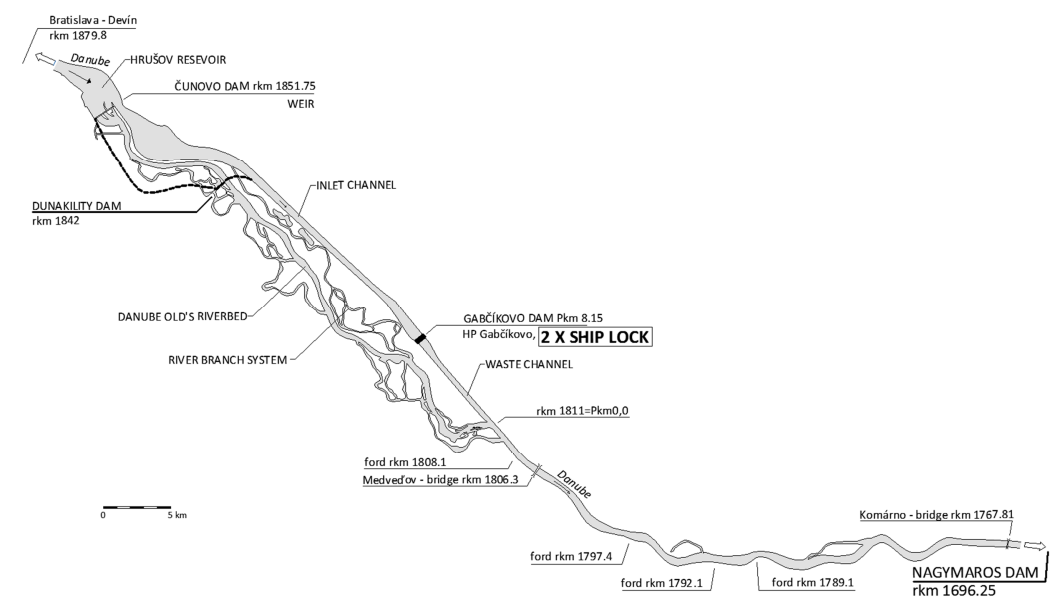

Fig. 2. Scheme of the Gabčíkovo project (GAP)

Energy regulatory functions of GAP (i.e. increasing or decreasing power of Hydro Power Plant (HPP) Gabčíkovo based on demand from electricity system) are very limited compared to original intentions, because Water Structure (WS) Nagymaros, 
which would create alignment reservoir, was not realized as planned [2]. Purpose of WS Nagymaros besides alignment of peak discharges from GAP was also to ensure cruise depth parameters on Danube section between GAP and WS Nagymaros. Result of missing Nagymaros system of water structures is that parameters of waterway (mainly depth) are directly affected by discharge manipulation on GAP, while at the same time operation of GAP cannot cause decrease of cruise depths under critical levels especially at ford sections of Danube. This can endanger safety of international transport on river Danube. Main effect on efficiency and reliability of cruise operation has Ship Locks (SL). It is clear from measures and calculations in [3] that currently used emptying type of ship locks causes exceeding of maximum allowed flow velocities in filling/emptying system by more than a half. This increased velocity causes damage to structure itself and on technology parts of ship locks. On one hand, this emptying type increases the efficiency of cruise operation by minimizing the time required for the whole cycle, while on other hand it also rapidly reduces reliability by increasing number of repair breaks during which traffic is on hold. Hydraulic system of filling and emptying is very complicated and with current trends in electricity trade, it is nearly impossible to operate GAP based on operator's experience. For operation of this scale and complicated structure it is necessary to use operation system (optimization tool), which will control discharge through objects so they will ensure the fastest possible crossing of boats via ship lock and along with load minimization on structures and technology of ship locks, i.e. optimization during filling or emptying and ensure safety of cruise operation on river (cruise depths above critical levels) on whole section of river affected by operation of GAP and simultaneously maximize profit from electricity production from hydropower plant, i.e. optimization of hydro energetic usage of GAP.

\section{Methods}

\subsection{Optimization of filling and emptying of ship locks}

Many parameters affect ship flow in Filling and Emptying System (F/ES) of ship locks: used type of F/ES, parameters of F/ES like geometry of individual parts of system, dimensions of individual parts (cross section of canals, route of canals, connection of canals, amount, area and position of ceiling locks of canals, amount, area and position of cross pipes and dimensions of locks on them, resistance characteristics). It is clear from physical principle of F/ES that filling and emptying has more parameters than those already mentioned above, that also have significant impact on shape of curve of function of opening of inlet and outlet locks.

\section{Formulation of optimization problem}

Each and every cycle of boat passing ship locks is optimization task. Goal of this task is to get boats through ship locks and simultaneously minimize load on construction and technology of F/ES of ship locks. Since these goals are contradictory, it is necessary to use multi-criteria optimization model, which can be mathematically described as: 


$$
F=w_{1} T+w_{2} v_{\max } \rightarrow \min .
$$

where $F$ is the multi-criteria (target) function representing the goal, which must be achieved while taking into account restrictions of ship locks; $T$ is the time needed to fill/empty of ship lock; $v_{\max }$ is maximum velocity of ship flowing in canals of F/ES and $w_{1}$ and $w_{2}$ are weight coefficients of optimization criteria. Result of optimization of function $F(1)$ is finding optimal process of opening of locks, during which velocities will not exceed critical speeds and simultaneously time needed to pass GAP for boats will be as short as possible.

Optimization model of filling and emptying process of SL

Mathematical description of function $F(1)$ has to come out from premise of theory of filling and emptying Water Level (WL) with outlet under Ship Level (SL) in SL with nonlinear opening of inlet and outlet locks. For calculation of F/ES of SL premise is used that for elementary volume $d V$ takes $d t$ time to flow from one 'vessel' to another. This is described by two differential equations, dynamic equation (2) and equation of continuity (3),

$$
\begin{aligned}
& d V=\mu \cdot f \cdot \sqrt{2 g y} d t, \\
& d V=-F_{S} \cdot d y,
\end{aligned}
$$

where $t$ is time from beginning of filling/emptying [s]; $\mu$ is coefficient of losses during filling/emptying of $S L ; F_{S}$ is flow area of SL $\left[\mathrm{m}^{2}\right]$; and $f$ is flow area of inlet/outlet $\left[\mathrm{m}^{2}\right]$. Basic scheme for filling/emptying calculation of SL can be seen in Fig. 3, where $f_{l}$ is the flow area of bypass $\left[\mathrm{m}^{2}\right], T$ is time taken to fill/empty SL [s]; $H_{0}$ is slope at the beginning in SL; and $y$ is immediate slope in SL in time $t$ [m]. Time for emptying SL while outlet shutter are opening nonlinearly can be described with differential equation:

$$
T=\frac{-F_{S}}{\mu(y, f, \cdots) \cdot f(t) \cdot \sqrt{2 g}} \int_{0}^{H_{0}} \frac{d y}{\sqrt{y}} .
$$

To calculate immediate inflow into ship lock, following equation is used:

$$
Q=\mu(y, f, \cdots) \cdot f(t) \cdot \sqrt{2 g y} .
$$

It is possible, based on equations above, to formulate optimization model of emptying of SL as follows: 


$$
F=w_{1} \frac{-F_{S}}{\mu(y, f, \cdots) \cdot f(t) \cdot \sqrt{2 g}} \int_{H_{0}}^{0} \frac{d y}{\sqrt{y}}+w_{2} \frac{[\mu(y, f) \cdot f(t) \cdot \sqrt{2 g y}]_{\max }}{S} \rightarrow \min
$$

where $S$ is flow area of bypass at the maximum inflow into SL.

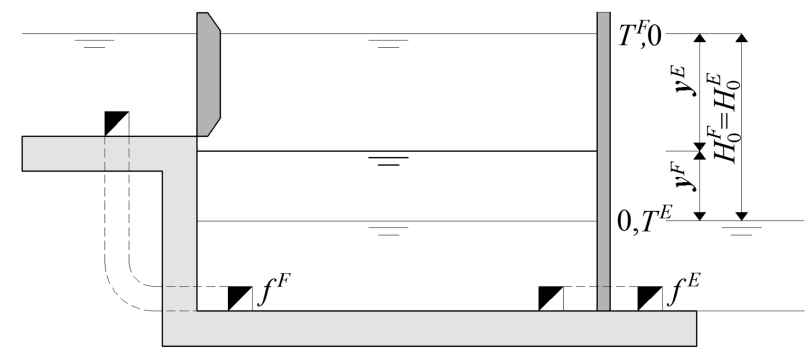

Fig. 3. The filling and emptying scheme

Target function (6) is also limited by following restrictions:

$$
v_{\max } \leq \overline{v_{\max }}, \quad f(t) \leq f_{\max }, \quad t \leq t_{T},
$$

where $\overline{v_{\max }}$ is highest ship flow velocity acceptable in filling canals of SL; $f_{\max }$ is maximum area of outlet; and $t_{T}$ is maximum opening time of inlet shutter. Analogically, it is possible to derive equations for filling out of equations (2) and (3). In Fig. 4, general equations for optimal manipulation with valves are shown.

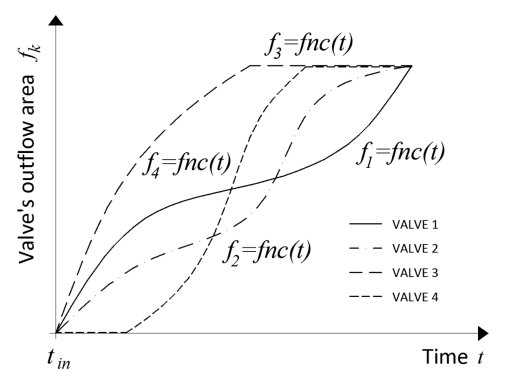

Fig. 4. General equations for optimal manipulation with valves

\section{Methods of solving the optimization}

Target function (6) can be defined as nonlinear optimization problem with nonlinear restriction conditions and difficult shape of target function. What mainly makes this problem complicated, is nonlinear shape of function and interconnection between coefficients of filling/emptying of SL; inflow/outflow from SL and sought-after 
function of opening of valves $f(t)$. Since the target function describing this problem has difficult surface shape, analytical solution to this problem is literally impossible.

In case of complicated large-scale problems, classical (numerical) optimization methods encounter many complications like curse of dimensionality despite fact, that while solving less complicated problems provide high effectiveness. Solving filling optimization of single SL using Mixed Integer Linear Programming (MILP) is published in [4].

To solve multi-parameter optimization functions with 'wild' function shape and many extremes or with unknown gradient, for which does not exist specific algorithm or linear numerical method, heuristic optimization methods are mainly used, for example, Particle-Swarm Optimization (PSO), Ant Colony Optimization (ACO), Simulated Annealing (SA) and others. Heuristic methods are characterized by having kind of intelligence, thus they are categorized as artificial intelligence methods. Optimization of filling SL is using, PSO are described in [5], [6], ACO was used in [7], original heuristic control algorithm in [8] and simulated annealing in [9]. Solving optimization based on combination of simulated annealing and Mixed Integer Non-Linear Programming (MINLP) was used to optimize SL of the Tree Gorges Dam in [10]. Using fuzzy logic algorithms are described in [11].

Among the most representative heuristic optimization methods are Genetic Algorithms (GA). These algorithms simulate principle of natural selection proposed by Charles Darwin, which lead to better and better organisms. GA uses similar principle to search for best solution to technical and other problems. More on using GA to optimize filling and emptying of SL can be found in [6].

To use GA to solve function (6), it is necessary to transform this function into pseudo fitness function $\varphi$ :

$$
\begin{aligned}
\varphi= & -\left(w_{1} \frac{-F_{S}}{\mu(y, f, \cdots) \cdot f(t) \cdot \sqrt{2 g}} \int_{H_{0}}^{0} \frac{d y}{\sqrt{y}}+w_{2} \frac{[\mu(y, f, \cdots) \cdot f(t) \cdot \sqrt{2 g y}]_{\max }}{S}\right) \\
& -W_{\text {pen }} \sum_{\lambda=1}^{A} s_{\lambda} p
\end{aligned}
$$

where $\operatorname{pen}_{\lambda}$ is the penalization functions, which replaces restriction conditions, $W_{p e n}$ is the weight factor of penalization; $A$ is the number of restrictions; and $s_{\lambda}$ is the factor representing weight of strictness of adhering individual restrictions. Using mutual ratio of weight factors, it is possible to 'toughen' or 'lighten' individual restrictions.

\subsection{Optimization of hydro-energetic use of GAP}

\section{Formulation of optimization problem}

Target function describing main goal of optimization (maximum profit from electricity) can written as follows: 


$$
F=\sum_{i=1}^{T} c_{i} \cdot P_{H P G i}\left(Q_{H P G i}, H_{H P G i}\right) \rightarrow \max
$$

where $c_{i}$ is the price of electricity in $i^{\text {th }}$ hour; $P_{H P G i}$ is the power of GAP in $i^{\text {th }}$ hour; $Q_{H P G i}$ is the discharge through GAP in $i^{\text {th }}$ hour (target variable); and $H_{H P G i}$ is net slope on GAP in $i^{\text {th }}$ hour.

Optimization model of hydro-energetic operation of GAP

Fig. 5 represents hydropower scheme of GAP.

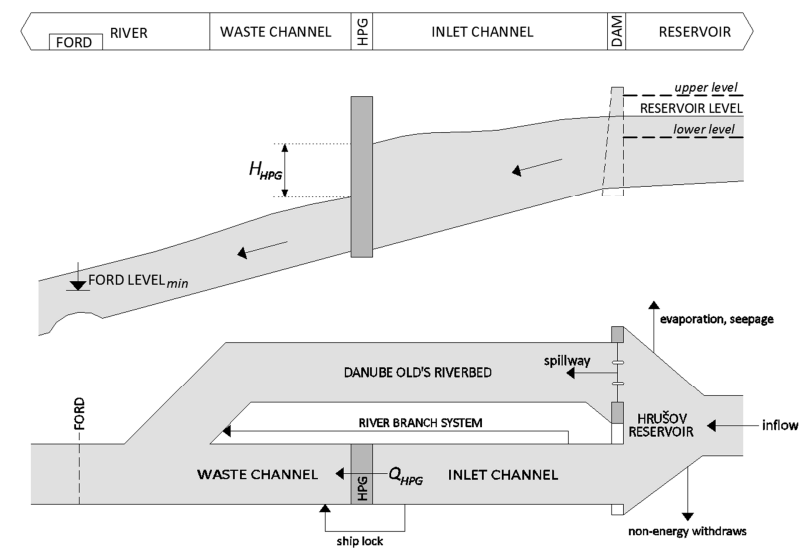

Fig. 5. Hydropower scheme of GAP

Target values of discharges through GAP ' $Q_{H P G i}$ ' (i.e. operation plan of GAP in one hour raster) are results of maximization of target function (9), which must be modified by restriction conditions that comes from operation manual of GAP. These restrictions also include safety for boats on ford sections of river Danube i.e. $F O R D_{-} L E V E L>=F O R D_{-} L E V E L_{\min }$. Target function (9) modified with restrictions can be described as integer nonlinear problem with nonlinear restriction conditions. Source of nonlinearity of problem is complicated connection between discharge and power output of GAP. Changes in discharge through GAP caused by variable power demand from power grid cause unsteady flow, which causes changes in upper and lower water levels on GAP. These changes affect immediate actual slope on hydropower plant thus also affect effectiveness of energy conversion and total output of hydropower plant. It is possible to mathematically describe one dimensional unsteady flow with free water level on target section of Danube (from Bratislava - Devin to Komárno - bridge) using system of Saint-Venant partial differential equations:

$$
\frac{\partial Z}{\partial x}+\frac{1}{g} \frac{\partial U}{\partial t}+\frac{U}{g} \frac{\partial U}{\partial x}=\frac{U|U|}{C^{2} R}, \text { and } \frac{\partial Q}{\partial x}+\frac{\partial S}{\partial t}=0,
$$


where $Z$ is the water level in cross-section $[\mathrm{m}] ; x$ is the distance of cross-section from beginning $(x=0)$ in direction of flow [m]; $U$ is the average velocity of water flowing in cross-section $\left[\mathrm{m} . \mathrm{s}^{-1}\right] ; t$ is the time $[\mathrm{s}] ; g$ is the gravitational acceleration $\left[\mathrm{m} . \mathrm{s}^{-2}\right] ; C$ is the velocity coefficient; $R$ is the hydraulic radius $[\mathrm{m}]$; $\mathrm{Q}$ is the discharge in river $\left[\mathrm{m}^{3} \cdot \mathrm{s}^{-1}\right]$; and $S$ is the area of cross-section $\left[\mathrm{m}^{2}\right]$. After updating equations set (10) with correctly chosen boundary conditions and initial conditions it is possible to calculate discharge and water level development over time in ay desired cross-section of river Danube in target section.

\section{Methods of solution of optimization}

Classical numerical methods of optimization cannot be used to solve this problem, because of complexity of mathematical expression of unsteady flow with free water level using Saint-Venant equations. Fig. 6 represents block scheme of optimization model of hydro-energetic operation of GAP using genetic algorithms to maximize target function (9). Since GA only allow to solve unbounded problems, it is necessary to transform boundaries using penalization functions (so called penalizations), which will penalize over-running or under-running of solution boundaries.

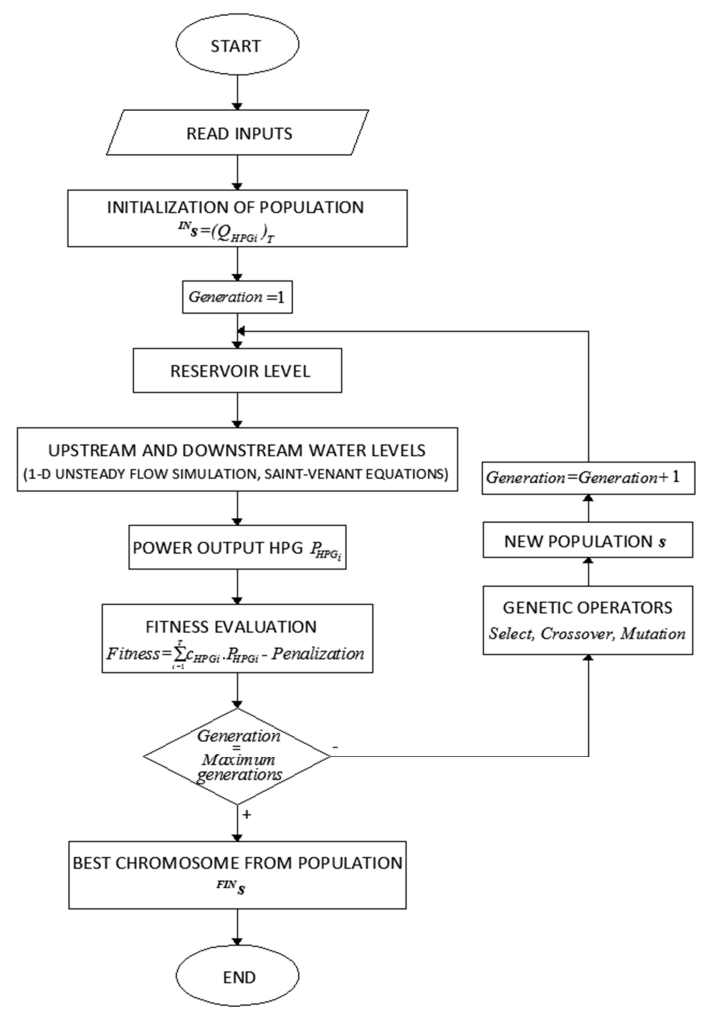

Fig. 6. Block scheme of optimization of the Gabčíkovo project operation 


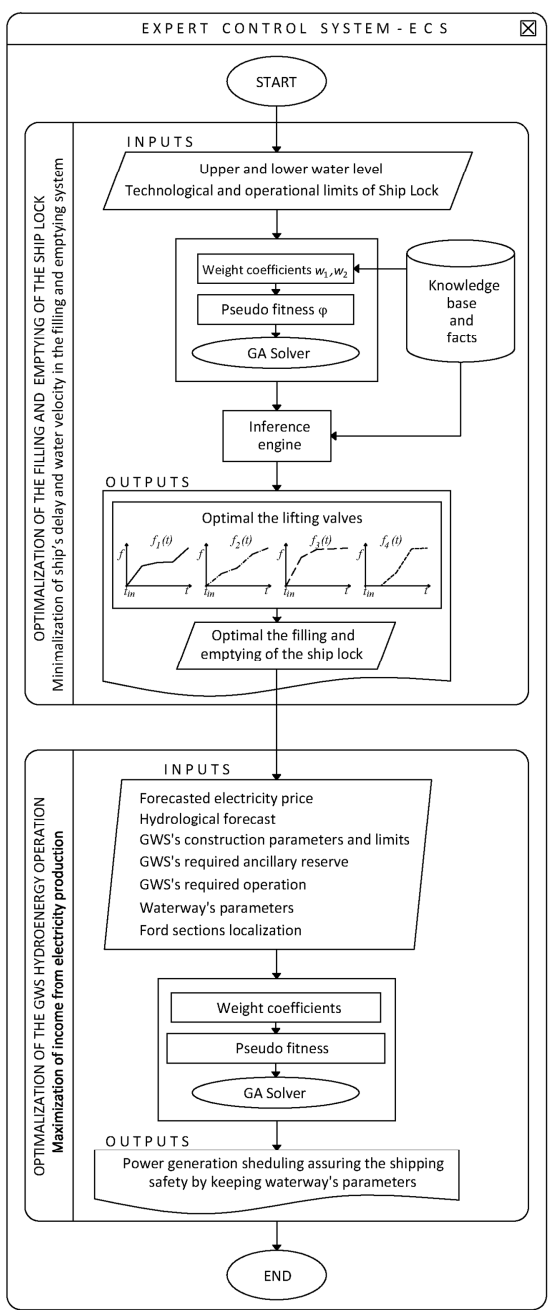

Fig. 7. Block scheme of expert control system of the shipping operation

Primary inputs of optimization model of filling/emptying of SL are:

- Immediate water level in upper and lower roadstead of SL in time of initialization of optimization calculation (measured values);

- technological and operation restrictions of SL;

- experience and knowledge from real operation of SL;

- data sets about operation of SL (for example results of 3D simulations of filling/emptying of SL).

Primary outputs of optimization model of filling/emptying of SL are: 
- optimal time course of manipulation with inlet and outlet shutters of filling/emptying system of SL;

- optimal time course of filling/emptying of SL (serves also as input into optimization of hydro-energetic operation of GAP).

Primary inputs for optimization of hydro-energetic operation of GAP are:

- optimal time course filling/emptying of SL (input from filling/emptying optimization);

- valuation of energy in hour step according to business diagram;

- hydro-prognosis in cross-section Bratislava - Devin;

- construction parameters and limits of GAP, i.e. shutdowns and limitations of technological equipment;

- required values for support services on GAP;

- $\quad$ required manipulation on GAP objects (water abstractions and water levels);

- $\quad$ parameters of shipping way;

- localization of ford sections on river.

Primary outputs of optimization of hydro-energetic operation on GAP are:

- assumption of splitting discharge of Danube between GAP and original Danube riverbed and plan for electric production on GAP while taking into account regulation reserve in 1 hour time raster (while still securing all boundary, hydroenergetic and shipping restrictions);

- time course of discharge and water level regime on Danube on target section (from Bratislava - Devin to Komárno - bridge).

\section{Conclusion and suggestions}

Based on processing of proposals for solving actual condition of operation system of shipping and energy operation of GAP, ECS must with help of optimization of filling/emptying of SL secure fast and safe overpass for ships through SL along with minimizing load on construction parts of filling/emptying system.

- Result of optimization must be finding optimal course of opening (in advance known amount of shutters) where there will be no violation of following restriction;

- average profile velocity of water in filling/emptying system of SL (highest permissible velocity was set by planner at $10 \mathrm{~ms}^{-1}$ );

○ there will be no vacuum and cavitation on propellers of hydropower plant along with preserving following filling/emptying times (with 23,6 m slope):

- using 4 channels 13 minutes at most;

- using 2 channels 20 minutes at most;

- Optimization must be solved using heuristic methods (for example genetic algorithms), this is because of complex multi-criteria target function; 
- Because of slope conditions on GAP, ECS must evaluate course of optimal shutter opening in real time, always for actual value of slope;

- ECS must be capable of redefining course of optimal shutter opening and provide advice and recommendations for optimal choice based on empirical experience of the GAP operator i.e. based on 3D simulations of filling/emptying of SL;

- All shutters must be controllable in a way that will allow nonlinear opening of these shutters i.e. it is needed to control speed of opening according to nonlinear function of time-outlet area 'time-outlet area' or 'time-position of shutter'.

ECS must be capable of evaluating effect of GAP on water level and discharge regime of Danube section from Devin to Komárno and thus secure safe shipping operation:

- Result of simulation of discharge and water level regime on section of Danube must review, if planned manipulation with discharges on objects of GAP in given time window will not cause limitation of shipping way parameters (falling below lower limit of water level on ford sections);

- ECA must work with high precision of simulations (most important is water level regime), because safe distance of ships from riverbed to ship bottom on fords is $20 \mathrm{~cm}$. Maximum deviation of simulation has to be $-10 \mathrm{~cm}$ (water level is $10 \mathrm{~cm}$ lower in reality) or $+20 \mathrm{~cm}$ (water level is $20 \mathrm{~cm}$ higher in reality);

- Because of complexity of problem of hydraulic system of GAP, discharge and water level regime must be solved exclusively by mathematical apparatus describing unsteady flow of water in open channels using Saint-Venant equations complemented with correct boundary conditions and primary conditions. Any approximation of unsteady flow using simplified models of water flow would cause with highest probability gross simplification of results of modeling and thus cause increased risk of violating parameters of water way (especially on ford sections);

- Besides base energy production on GAP, it's important to take into account while simulating water level regime also supports services;

- ECS must dispose with functions capable of most accurate transformation of power parameters required values of regulation reserves of GAP to ensure support services and their volume equivalents;

- ECS must work with real and actual status of riverbed of Danube and reservoir Hrušov and with exact localization of ford sections and their parameters, because this is changing overtime due to erosion and sediment transport. Up-todate of river bed morphology must be done annually after evaluation of riverbed done by Slovak Water Management Company and after each and every pass of riverbed forming discharge.

\section{Acknowledgements}

This paper was supported by the Grant agency VEGA under contract No. 1/0361/17. 


\section{References}

[1] Tkáč Š., Sečka L., Vranayová Z. Hydro-energy in Slovak republic and Taiwan R.O.C., Pollack Periodica, Vol. 9, No. 3, 2014, pp. 59-70.

[2] Červeňanská M., Baroková D., Šoltész A. A modeling the groundwater level changes in an area of water resources operations, Pollack Periodica, Vol. 11, No. 3, 2016, pp. 83-92.

[3] Možiešik L', Šulek P., Orfánus M., Hruštinec L'. Upgrade of Gabčíkovo locks, Feasibility Studie, Slovak University of Technology in Bratislava, Bratislava, 2017.

[4] Hermans J. Optimalisatie van binnenscheepvaart, Master Thesis, Katholieke Universiteit Leuven, 2008.

[5] Kanović Ž., Bugarski V., Bačkalić T., Jeličić Z., Petković M. , Matić D. Optimization of ship lock control system using swarm-based techniques, Journal on Processing and Energy in Agriculture, Vol. 18, No. 1, 2014, pp. 30-35.

[6] Kanović Ž., Bugarski V., Bačkalić T. Ship lock control system optimization using GA, PSO and ABC: A comparative review, Promet - Traffic\&Transportation, Vol. 26, No. 1, 2014, pp. 23-31.

[7] Liu R. J., He D. D., Wang L. J., Xu H. Y. Ant colony optimization applied to the three Gorges ship lock arrangement optimization, Applied Mechanics and Materials, Vol. 543547, 2014, pp. 1663-1666.

[8] Ting C., Schonfeld P. Integrated control for series of waterway locks, Journal of Waterway, Port, Coastal and Ocean Engineering, Vol. 124, No. 4, 1998, pp. 199-207.

[9] Kosmas O. T., Vlachos D. S. Simulated annealing for optimal ship routing, Computers \& Operations Research, Vol. 39, No. 3, 2012, pp. 576-581.

[10] Zhang X., Qi H., Fu X., Yuan X. Hybrid algorithm to minimize total weighted wait-time of ships for navigation co-scheduling in the three Gorges project, Proceedings of International Conference on Transportation Engineering 2007, Southwest Jiaotong University, Chengdu, China, July 22-24, 2007, pp. 2759-2764.

[11] Bugarskia V., Bačkalić T., Kuzmanova U. Fuzzy decision support system for ship lock control, Expert Systems with Applications, Vol. 40, No. 10, 2013, pp. 3953-3960. 